\title{
Administrators' Reports of School Context in the Early Education Longitudinal Study (EELS)
}

\author{
Ju-Lee A. Wolsey ${ }^{1}$, Daqian Dang' ${ }^{2}$, Hannah A. Joharchi ${ }^{3}$, M. Diane Clark1 \\ ${ }^{1}$ Department of Deaf Studies and Deaf Education Lamar University, Beaumont, TX, USA \\ ${ }^{2}$ Department of Educational Psychology George Mason University, Fairfax, VA, USA \\ ${ }^{3}$ Department of Psychology Gallaudet University, Washington DC, USA \\ Email: "jwolsey@lamar.edu, ddang6@gmu.edu, hannah.joharchi@gallaudet.edu, diane.clark@lamar.edu
}

Received 23 October 2015; accepted 26 December 2015; published 29 December 2015

Copyright ( 2015 by authors and Scientific Research Publishing Inc.

This work is licensed under the Creative Commons Attribution International License (CC BY). http://creativecommons.org/licenses/by/4.0/

\section{(c) (i) Open Access}

\section{Abstract}

The goal of the current project was to investigate the characteristics of a cohort of school administrators whose schools participated in the Early Education Longitudinal Study (EELS) conducted by the National Science Foundation's Science of Learning Center on Visual Language and Visual Learning (VL2) at Gallaudet University. In the study, which was an outgrowth of the previous Annual Survey of Deaf and Hard of Hearing Children and Youth conducted at Gallaudet University from 1968 to 2004 , school administrators $(n=48)$ were asked to describe the features of their early education programs for deaf children and to characterize the student populations they served. Descriptive statistics were calculated to report the results. The administrators surveyed reported that most of the children served were delayed in their language development, many of whom were extremely delayed and in need of language remediation. The data challenge the field of deaf education, especially early childhood education, in investigating the evidence-based practice that will help develop deaf and hard of hearing children to achieve their full learning potential.

\section{Keywords}

Early Education Longitudinal Study (EELS), Annual Survey, School Administrator, Deaf and Hard of Hearing, Children, Early Childhood Education

\footnotetext{
${ }^{*}$ Corresponding author.

How to cite this paper: Wolsey, J. A., Dang, D. Q., Joharchi, H. A., \& Clark, M. D. (2015). Administrators' Reports of School Context in the Early Education Longitudinal Study (EELS). Psychology, 6, 2103-2112.

http://dx.doi.org/10.4236/psych.2015.616206
} 


\section{Introduction}

Historically, an annual survey was conducted to allow schools and their administrators to plan services for deaf and hard of hearing children and youth, originally by the Office of the Annual Census of Hearing Impaired Children, which then became the Office of Demographic Studies, followed by the Center for Assessment and Demographic Studies, which finally became the Gallaudet Research Institute (GRI) (Holden-Pitt \& Diaz, 1998). Regardless of the title of the office, the name of the survey was the Annual Survey of Deaf and Hard of Hearing Children and Youth. This survey started in 1968 to provide an annual national database for educators and researchers in the United States (U.S.) to track deaf and hard of hearing school age children and their characteristics (Holden-Pitt \& Diaz). The survey was initially supported by what is now the Department of Education (formerly the Bureau of Education for the Handicapped and later the National Institute of Education). Beginning in 1975, the Annual Survey was funded by Gallaudet University in Washington DC.

The goals of the Annual Survey were to provide demographics to be used for educational planning at the local, state, and national levels (Holden-Pitt \& Diaz, 1998). Important components of this survey focused on audiological levels found among deaf and hard of hearing children, as well as the kinds of educational programs that provided service to these students. This database was disseminated through the GRI and served as a source of information for many researchers to document the need for their efforts.

While the majority of deaf and hard of hearing children were in residential and day schools at the start of the Annual Survey in 1968, the Public Law (P.L.) 94-142 and the Americans with Disabilities Act (ADA) of 1990 allowed more students to be educated and mainstreamed in regular public schools with hearing peers (Holden-Pitt \& Diaz). The percentage of deaf and hard of hearing students attending special schools declined by more than half in the last quarter century (Mitchell \& Karchmer, 2006). Despite tremendous changes with the Annual Survey over thirty years, tracking the trends of deaf and hard of hearing children was critical. But with new technologies, terminology, communication methods, and new research, the Annual Survey was updated to continue to track vital information. Therefore, the Annual Survey evolved and included information regarding cochlear implants, additional disabilities, parental hearing status, the primary mode of communication used in the classroom, and additional services provided to deaf and hard of hearing children (Mitchell, 2004).

After the passage of P.L. 94-142, the Individuals with Disabilities Education Act (IDEA), the U.S. Department of Education required that children receiving special education services should be tracked through state reports. This report came to be known as the Child Count report (Mitchell, 2004). However, Child Count data were aggregated from state-level reports; therefore was not useful for more targeted data analysis. In addition, demographic and program specific information was not provided in Child Count (Mitchell, 2004).

The GRI Annual Survey, while it contained the records of individual children, used annual cross-sectional data analyses and did not systematically follow individual children to be able to determine their educational progress. In addition to aggregating data, the Child Count data did not include children from birth to the age of five. Therefore, the National Center for Special Education Research (NCSER), under the Institute for Education Science, in 2006 (Markowitz et al., 2006) developed and conducted the Pre-Elementary Education Longitudinal Study (PEELS) of children between the ages of three to six who had disabilities. These children were followed for six years to determine their educational outcomes.

Initially, researchers who had been part of the Annual Survey and were currently working in the Science of Learning Center on Visual Language and Visual Learning (VL2) investigated the potential uses of this database to better understand the characteristics of successful deaf and hard of hearing children. Given the low incidence of children who have a hearing loss in comparison to other types of disabilities, there was not enough data to use this database for this comparison. Additionally, PEELS did not ask questions like those found in the Annual Survey or questions regarding the use of visual language and visual learning strategies. Therefore, VL2 used PEELS as a model and created the Early Education Longitudinal Study (EELS). Importantly, researchers from both the Annual Survey and the PEELS study were part of the team that developed EELS. Complete information on the methods used in EELS can be found on the VL2 website (http://vl2.gallaudet.edu/files/2914/1045/8608/EELS Methods Paper.pdf) in a white paper by Allen, Morere, Clark, \& Murphy (2014). The goal of the EELS project was to follow young children to better understand the precursors of later educational success. EELS included direct psychological assessments of children, as well as parent, teacher, and program administrator surveys. This paper looks at the responses to 14 questions on the administrator's questionnaire about their school and program characteristics. Given that the last Annual Survey was in 2004, this information became important to obtain administrators' re- 
ports regarding their programs.

\section{Research Question}

How do program administrators in schools serving pre-school-aged children selected for a large national longitudinal study describe the school context of their programs?

\section{Method}

\subsection{Participants}

Upon approval by the Institutional Review Board, schools were recruited to participate in the EELS project. The EELS team contacted principals or program directors at schools that participated in either the Gallaudet Research Institute Annual Survey of Deaf and Hard of Hearing Children and Youth or the American Annals of the Deaf program directory. Of the 32 schools in 25 states that participated in the study, 251 children between the ages of 3 to 5 were involved in the project. Administrators from each program were asked to complete the Early Childhood Program Administrator Questionnaire if one or more children in their program were involved in this project. This sampling lead to 48 administrators across the 32 schools as some schools had more than one program participating in the EELS project. Administrators were not asked questions about individual children participating in the study; therefore, the resulting data included 48 different principals and administrators who completed the survey, which were located in the 32 participating schools. These schools were located across the U.S. and in various community types: $21.3 \%$ were from rural communities; $25.5 \%$ in small or medium-sized cities; $36.2 \%$ in large or very large cities, $14.9 \%$ in the suburbs; and $2.1 \%$ (only one school) on an Indian Reservation. Administrators were compensated $\$ 10$ for completing a brief survey regarding the characteristics of their program.

\subsection{Materials and Procedures}

The Early Childhood Program Administrator Questionnaire was used to collect data from principals or program directors (i.e., school administrators). This survey was made up of several components. These components included open-ended and semi-structured questions; twelve of the items were multiple-choice questions, two were short answer questions, and the remaining part of the survey included the original 47-item Beliefs and Attitudes about Deaf Education (BADE) survey. The BADE asked respondents about beliefs and attitudes about early intervention services, communication options, language choices, school placements, support services, and assistive technology that pertained to deaf and hard of hearing children; but this information is not reported here (for information on administrators responses to the BADE, see Clark, Baker, Choi, \& Allen, 2013). These items have been vetted in the GRI Annual Survey of Deaf and Hard of hearing Children and Youth. The questions have historically been used to obtain demographic data on deaf and hard of hearing students and the types of programs in which they are educated. Reliability for the BADE can be found in Clark et al., but again this information is not reported here. Participants either completed the questionnaire online with the provided password or by paper copy, which was returned to the EELS team. Questionnaires took approximately 20 minutes to complete.

\subsection{Data Analytic Plan}

Descriptive statistics were conducted to determine percentages to the questions on the survey. Open-ended questions are presented in summary format.

\section{Results}

Results from remaining parts of the Early Childhood Program Administrator Questionnaire provided characteristics of the 32 schools in the EELS project that had early childhood education programs for deaf and hard of hearing children. Again, we focused on the fourteen open ended and semi-structured questions on the survey. The first question (Question A) asked "Which of the following best describes the agency or organization that operates your program?” Respondents ( $=46$ ) chose one of the four types of agency or organization while two respondents did not provide an answer. Data is summarized in Table 1. Most of the programs included in EELS were public agencies that focused on providing educational services to young children. 
Table 1. Types of agency or organization.

\begin{tabular}{ccc}
\hline Type & Number of Responses & Percent of Responses \\
\hline Public agency related to education & 33 & $69 \%$ \\
Public agency & 0 & $0 \%$ \\
Private non-profit for organization & 11 & $23 \%$ \\
Private profit for organization & 2 & $4 \%$ \\
Total & 46 (2 respondents did not provide an answer) & $96 \%$ (does not include 2 missing responses) \\
\hline
\end{tabular}

Question B listed five options, including other, to the statement "Your program is.” (see Table 2). Administrators from four different programs provided additional responses. These responses included: Hearing-Impaired Itinerant (Auditory-Verbal Therapy: AVT), Audiology multi-district, families' first-home visits through a School for the Deaf, Public School District, and Itinerant deaf education teachers. Data is summarized in Table 2. Out of the 48 respondents, two did not respond. Given the original recruiting pool, it is not surprising that over $50 \%$ of the programs were located at one site, rather than having service delivery at multiple sites.

Question C asked a yes and no question to "Does your program currently receive federal funds?” Ten administrators responded yes (21\%) while 35 did not receive any federal funds (73\%). This response is supported by the data in the EELS project, as more than $25 \%$ of the children were from homes that had income levels below the poverty line. Three respondents did not choose either option.

Question D asked "Which of the following best describes the community in which your program is located?" Eight options were provided but respondents were to choose one option (see Table 3 for responses). About a quarter of all programs were in larger cities, most likely related to the need to have enough young deaf and hard of hearing students in one location to support the programs.

Question E asked participants to respond to the statement "Indicate which programs/classrooms for children ages 3 through 5 are offered by your school, agency, or organization.” There were seven options to choose from and respondents checked all that applied to their schools. All participants $(n=48)$ responded and the results are summarized in Table 4. The majority of the programs were center-based preschools; about two-thirds of the programs were for deaf and hard of hearing children, while the remaining one-third reported that their programs were primarily for hearing children.

Question G provided four options to the question "In your state, which professionals most often provide direct educational services to deaf or hard of hearing infants and toddlers birth — three years of age?” All participants $(n=48)$ responded and their responses are summarized in Table 5. Notice that the most common service providers for direct educational service to deaf and hard of hearing infants focused on speech and hearing.

Question $\mathrm{H}$ asked respondents a yes or no question, “Does your program provide home intervention?” Twentysix administrators responded yes (54\%) while 21 did not provide home intervention (44\%). All but one participant responded to the question. In addition, participants who responded yes to the statement were also asked to respond to the following question; "If yes, please list what curriculum you use for home intervention.” These curriculums included: My Baby and Me, a Moog Curriculum; State Approved Early Childhood Curriculum; Help Hawaii Early Learn; Parent Infant Communication; High Scope; Hodge Podge; Learning to Talk; Around the Clock; the Sun Shine Curriculum; and Baby Talk. It was also found that some administrators ( $\mathrm{n}=17)$ used the Sensory Kids Impaired Home Intervention (SKI-HI) Curriculum.

Question I asked participants "Other than home interventions, check those services your program provides to family members." Fourteen options were provided to allow participants to check all that applied (see Table 6 for responses). Three participants did not respond. Findings show that teaching ASL to families, as well as helping them to develop connections to the Deaf community were reported by more than half of all the administrators, suggesting that more bilingual schools were included in the sample. 
Table 2. Types of early childhood programs.

\begin{tabular}{|c|c|c|}
\hline Type & Number of Responses & Percent of Responses \\
\hline A single site & 25 & $52 \%$ \\
\hline Part of a larger agency that provides early childhood programs in more than one site & 7 & $15 \%$ \\
\hline Part of a multiservice agency that provides in addition to early childhood programs & 14 & $29 \%$ \\
\hline Other & 2 & $4 \%$ \\
\hline Total & 48 & $100 \%$ \\
\hline
\end{tabular}

Table 3. Types of communities where the schools are located.

\begin{tabular}{|c|c|}
\hline Type & Percent of Responses \\
\hline Rural community & $21.3 \%$ \\
\hline Small or medium-sized cities & $25.5 \%$ \\
\hline Large or very large cities & $36.2 \%$ \\
\hline Suburb & $14.9 \%$ \\
\hline Military base or station & $0 \%$ \\
\hline Indian reservation & $2.1 \%$ \\
\hline Total & $100 \%$ \\
\hline
\end{tabular}

Table 4. Types of programs/classrooms offered for 3 to 5 years old children.

\begin{tabular}{|c|c|c|}
\hline Type & Number of Responses & Percent of Responses \\
\hline Center-based preschool program primarily serving hearing children & 19 & $40 \%$ \\
\hline Center-based child care program primarily serving hearing children & 2 & $4 \%$ \\
\hline $\begin{array}{c}\text { Center-based preschool program primarily serving children who are deaf or } \\
\text { hard of hearing }\end{array}$ & 33 & $69 \%$ \\
\hline $\begin{array}{c}\text { Center-based child care program primarily serving children who are deaf or } \\
\text { hard of hearing }\end{array}$ & 2 & $4 \%$ \\
\hline Home-based program serving children who are deaf or hard of hearing & 10 & $21 \%$ \\
\hline Clinic service provider (e.g., occupational therapy, speech and language, etc.) & 11 & $23 \%$ \\
\hline Other & 0 & $0 \%$ \\
\hline
\end{tabular}

Table 5. Types of professionals who provide direct educational services.

\begin{tabular}{ccc} 
Type & Number of Responses & Percent of Responses \\
Speech pathologist & 27 & $56 \%$ \\
Audiologist & 12 & $25 \%$ \\
Special education teacher & 9 & 26 \\
Teacher of the Deaf & $54 \%$ \\
\hline
\end{tabular}

Question J was, "Please list what curriculum you use in your preschool educational program for deaf or hard of hearing children ages 3 - 5 years.” Respondents provided an extensive list of curriculums. These included: Language for Learning (SRA Reading Mastery and Connecting Math); the Moog Curriculum; Minnesota State Standards; State Approved Early Childhood and General Education; State of California Preschool Curriculum; 
Table 6. Types of services that are provided to family members.

\begin{tabular}{ccc} 
Type & Number of Responses & Percent of Responses \\
\hline Parent support groups & 23 & $48 \%$ \\
American Sign Language classes & 26 & $54 \%$ \\
English-based sign classes & 9 & $19 \%$ \\
Classes on educational topics & 23 & $48 \%$ \\
Guest speaker series & 13 & $27 \%$ \\
Connections with Deaf community & 25 & $52 \%$ \\
Extended family learning opportunities & 8 & $17 \%$ \\
Membership in organizations for parents & 13 & $27 \%$ \\
Regularly produced newsletters & 22 & $46 \%$ \\
Parent lending library that includes educational materials for check-out & 26 & $54 \%$ \\
Childcare during school activities to support family involvement in activities & 15 & $31 \%$ \\
sponsored by your program & 12 & $25 \%$ \\
Parent advisory committee & 34 & $31 \%$ \\
\hline
\end{tabular}

School-developed curriculum; Mainstream Curriculum; Literacy Instruction-Direct Instruction Reading Program Everyday Math Curriculum; Teacher-developed and adapted curriculum; Dynamic Learning Map (DLM) 3 - 5 Reading Master for age 5, Assessment, Evaluation, and Programming Systems (AEPS) as needed; General Preschool curriculum; John Tracy Clinic; Purposeful Design Math Theme-based/Teacher created, Harcourt Brace Science Curriculum; Handwriting without Tears Brigance; SKI-HI; Pennsylvania State Standards; Local school district curriculum; Tennessee Early Learning Development Standards; Opening the World of Learning (OWL) Curriculum; Carolina Curriculum; Site based; Sunshine Curriculum; Language Adventure Curriculum; Read it Once, Read it Twice, Read it Once Again Curriculum; and Speech Perception Instructional Curriculum and Evaluation (SPICE) Curriculum.

Moreover, five different curriculums were reported by multiple respondents. These five curriculums included; Creative Curriculum ( $n=6$ ), Reggio Emilia Curriculum ( $n=3)$, Kendall Demonstration Preschool Curriculum (n $=3)$, New York State Standard Curriculum ( $n=2)$, and High Scopes 3 - 5 Curriculum $(n=2)$. Five administrators responded that their program did not have a curriculum and five others did not provide a curriculum name.

Question K asked participants, "When deaf or hard-of-children transition from birth-three programs, how would you assess their development upon enrolling in your program? Four options were provided; four participants did not choose an option. Data is summarized in Table 7. All administrators reported that children were delayed to some extent and as can be seen in Table 7, most of the programs were providing services to children who were extremely delayed in their language acquisition.

Question L stated, "Preschool programs may employ a variety of personnel to work with 3 - 5 years old. Check ALL that correspond to the kinds of preschool personnel who are employed by your program.” Nine options were provided and all participants selected at least one option. Data is summarized in Table 8. Importantly, these preschool programs were more likely to offer services related to audiology, rather than provide family support services.

Question M focused on socioeconomic status (SES) and read "What percentage of the children, ages 3 through 5 whom you serve, live in low-income households (e.g., receive income assistance or food stamps, free or reduced lunches)?” There were five options to choose from; one participant did not respond. This data is summarized in Table 9. Most programs involved in the EELS project had large proportions of deaf children from low-income families. 
Table 7. Assessment of deaf or hard of hearing children's developmental level.

\begin{tabular}{|c|c|c|}
\hline Developmental Level & Number of Responses & Percent of Responses \\
\hline $\begin{array}{l}\text { Children typically are on track; they are ready to learn. They have } \\
\text { acquired a fully functioning language system (spoken or signed) and } \\
\text { have achieved the milestones of normal language development. }\end{array}$ & 0 & $0 \%$ \\
\hline Children typically are delayed, but are still in the acceptable normal range. & 11 & $23 \%$ \\
\hline Children typically are slightly delayed, but catch up by kindergarten. & 9 & $19 \%$ \\
\hline $\begin{array}{c}\text { Children typically are very delayed, and much effort is needed in the area } \\
\text { of language remediation. }\end{array}$ & 24 & $50 \%$ \\
\hline Total & $\begin{array}{l}44 \\
\text { (two did not provide } \\
\text { a response) }\end{array}$ & $\begin{array}{l}92 \% \\
\text { (two did not provide } \\
\text { a response) }\end{array}$ \\
\hline Type & Number of Responses & Percent of Responses \\
\hline Teacher of the Deaf & 46 & $96 \%$ \\
\hline ASL specialist/coach & 16 & $33 \%$ \\
\hline Speech language pathologist & 43 & $90 \%$ \\
\hline Educational audiologist & 30 & $63 \%$ \\
\hline Sign language interpreter/s & 20 & $42 \%$ \\
\hline Behavior therapist & 14 & $29 \%$ \\
\hline $\begin{array}{c}\text { Counselors with specialization in working with deaf or hard of hearing children } \\
\text { or families }\end{array}$ & 19 & $40 \%$ \\
\hline Family support specialists & 8 & $17 \%$ \\
\hline $\begin{array}{l}\text { Teacher aides or other early childhood paraprofessional with expertise } \\
\text { in deaf education }\end{array}$ & 37 & $77 \%$ \\
\hline
\end{tabular}

Table 9. Socioeconomic status of children ages 3 through 5.

\begin{tabular}{ccc}
\hline Socioeconomic Status & Number of Responses & Percent of Responses \\
\hline Less than $25 \%$ & 7 & $15 \%$ \\
$25 \%-50 \%$ & 14 & $29 \%$ \\
$51 \%-75 \%$ & 9 & $19 \%$ \\
More than $75 \%$ & 10 & $21 \%$ \\
Don't know & 7 & $15 \%$ \\
Total & 47 (one did not provide a response) & $99 \%$ (one did not provide a response) \\
\hline
\end{tabular}

The last question $\mathrm{N}$ was a yes/no question, written as "Do you have an immediate family member who is deaf or hard of hearing (e.g., a spouse, partner, child, parent, or sibling)?” All 48 participants responded; 15 responded yes (31\%) to having a deaf or hard of hearing family member while 33 responded that they did not have any deaf or hard of hearing family members (69\%).

In summary, these administrators provided information not captured in the other three parts of the EELS project. For example, the names of the curriculums demonstrate that some programs are more oral than originally believed. Reports showed that one program was using Auditory-Verbal Therapy (AVT) while several others included curriculums from the Moog Center. As can be seen in the wide variability in the responses to the question about which curriculum a program used, there is no consensus about what students within deaf education programs should 
know by the end of their educational program. Some programs reported not using any standardized curriculum, while others reported adapting curriculum developed for hearing students.

\section{Discussion}

The picture obtained from these administrator reports is that many of their children are from low-income families who arrive at the program with delays in their language acquisition. The types of services provided often focused on speech therapy and audiological services; data supported by the most frequently reported Individualized Education Program (IEP) goals on the teacher surveys (Musyoka \& Clark, 2015). The sample of children in the EELS project includes a higher proportion of children at schools that are bilingual or provide education through some form of manual communication. Given this information, the administrators reported that some programs are using oral curriculums. Many of these administrators also reported that their program had no formally developed curriculum. This finding is not surprising, as oral programs have more well-defined language policies, which include formalized language plans (Nover, 2000). Therefore, it is easier to implement an AVT curriculum or a Moog Curriculum.

Most of the programs were federally funded and served a majority of children from low SES families. This finding is most likely related to the interesting representation that about one-fifth of the programs were in rural areas while one-third were in large or fairly large cities. Poverty in these areas has different impact on health and well-being (Amato \& Zuo, 1992), but having a deaf child in an already complicated life adds an additional stressor (Myers et al., 2010).

While these preliminary findings cannot be generalized, they do provide the rare perspective of school administrators, as well as a deeper picture of the early schooling experiences of these young deaf children who participated in the EELS project. In reviewing the three decade long legacy of annual survey data, Holden-Pitt \& Diaz (1998) found that the changes of the ADA brought more students freedom to be educated in either public schools with hearing peers or residential programs with deaf and hard of hearing peers (Holden-Pitt \& Diaz). Similarly, results indicate that there are a variety of different curricula and services offered to better meet the various needs of students and their families. As policy has progressed to meet the evolving needs of deaf and hard of hearing children and their families, so too have schools.

As Mitchell (2004) suggested, policy-delegated research should include the needs of the community it is serving or else, it may not serve the appropriate utility. For example, in following IDEA, states were to track progress of their students, yet the surveys developed were not for in-depth analysis (Mitchell). The findings in this study consider basic questions necessary to aide in the development of future surveys. Additionally, the results of this study do in fact provide some depth regarding specific responses of services and names of curricula.

This survey explored information regarding what types of programs and services that these schools offered. First, seeing as there is little to no information in this area of study, administrators were asked about general questions concerning their academic program such as the type of program they serve and where they obtain funding. While most of the school administrators could identify the curriculum used in their program, almost onefourth of the school administrators did not respond to this question, or responded stating that their program did not have a curriculum. This lack of curriculum highlights one of the issues regarding evidence-based programs for early childhood education (Spencer \& Marschark, 2010). Unfortunately a large number of schools do not have curriculum-based programs, and of those who do, not all are evidence-based in nature.

In addition, there were questions regarding specifically what types of services that these programs offer. The largest or most frequent service provided was for translation of materials into a language other than English. This finding is likely in response to the growing diversity and multilingual homes of deaf and hard of hearing children with parents come from a variety of nations. Services that were provided less often, but are still in high demand include: ASL classes, a parent lending library that includes educational materials for check-out, and connections with the Deaf community. These findings indicate that many to half of the individuals surveyed are involved with a program that is making efforts to provide some of the services that parents need.

\subsection{Implications}

While there are calls for evidence-based practice in deaf education regarding the early childhood years, there is little to no research in these areas. Implications for these findings include preliminary information regarding various programs from the perspectives of various school administrators. 
These findings help to clarify the educational experiences of young deaf and hard of hearing children in the EELS project. These reports give a snapshot of the kinds of programs and services that young deaf and hard of hearing children are provided. From these school administrators' viewpoints, most of the children are already delayed in their language and fully half of the administrators believed that they were extremely delayed and needed language remediation. This information challenges us to continue to search for evidence-based practices that will allow all deaf and hard of hearing children to achieve their fullest potential.

\subsection{Limitations and Future Research}

School administrators provided information regarding the school's programs for the children in the EELS project. Therefore, it should not be used to apply to all deaf education programs. However, these findings do provide insight into some of the services, resources, and curricula that programs have, as well as some areas that need more support. More in-depth information needs to be collected in order to better understand the variety of early childhood deaf education programs. Not only would more information in these areas inform researchers on directions for study regarding the development of evidence-based curricula, but could also provide information for the need for specific services (i.e. services that meet the growing needs of this diverse population).

Future research should not only include various demographic questions in order to collect information regarding the ethnicity, age, and other important information pertaining to the administrators themselves. In order to clarify the types of programs that are reporting data, questions related to language policy and language planning also need to include. In addition, a direct question asking how an administrator views their program would be helpful. This information could be verified by asking participating teachers the same question to determine if both teachers and administrators held the same beliefs. For example, LaSasso \& Lollis (2003) found that programs labeled themselves bilingual but did not have curriculum developed to support this designation.

\section{Conclusion}

In conclusion, there is a critical need for this kind of demographic information to be collected in order to provide information to educators, parents, and researchers. It is important that programs are surveyed annually, as they once were, as this can continue to provide information regarding educational programs for deaf and hard of hearing children in early childhood. Given that the last GRI Annual Survey was in 2004, there was no current information on the types of services provided to deaf and hard of hearing children. Funding and government agencies frequently ask for information on the characteristics of deaf and hard of hearing children in the U.S., and currently the answer is "we do not have that information". This situation should be addressed rapidly, as educational outcomes for deaf and hard of hearing children continue to lag behind their hearing peers (Qi \& Mitchell, 2011).

\section{Author Note}

Support for this project was provided by the National Science Foundation Science of Learning Center Program under Cooperative Agreements SBE-0541953 and SBE-1041725. Any opinions, findings, and conclusions or recommendations expressed are those of the authors and do not necessarily reflect the views of the National Science Foundation. The authors thank Drs Thomas Allen and Donna Morere who, along with Diane Clark, co-led the Early Education Longitudinal Study (EELS), which provided the data for the current study. We also thank the parents, teachers, school administrators, and children who participated in this study, without their support the project will not have been possible. We also thank all of the assessment and database team members-Leah Murphy-Swiller, Anna Crisologo, Amy Letteri, Song Hoa Choi, Sue Hotto, Gregory Witkin, Shilpa Hanumantha, Donna Guardino, Carly Ostrom, Melissa Anderson, Millicent Musyoka, Yunjae Hwang, Dorri Daggett, and Elizabeth Halper who gave of their time and talents to collect and score the assessment data and compile the database.

\section{References}

Allen, T. E., Morere, D. A., Clark, M. D., \& Murphy, L. (2014). The VL2 Early Education Longitudinal Study: Rationale, Methods, and Participant Characteristics. http://vl2.gallaudet.edu/files/2914/1045/8608/EELS Methods Paper.pdf

Amato, P. R., \& Zuo, J. (1992). Rural Poverty, Urban Poverty, and Psychological Well-Being. Sociological Quarterly, 33, 
229-240. http://dx.doi.org/10.1111/j.1533-8525.1992.tb00373.x

Clark, M. D., Baker, S., Choi, S. H., \& Allen, T. E. (2013). The Beliefs and Attitudes about Deaf Education (BADE) Scale: A Tool for Assessing the Dispositions of Parents and Educators. Psychology, 4, 1030-1038. http://dx.doi.org/10.4236/psych.2013.412150

Holden-Pitt, L., \& Diaz, J. A. (1998). Thirty Years of the Annual Survey of Deaf and Hard of Hearing Children and Youth: A Glance over the Decades. American Annals of the Deaf, 143, 71-76. http://dx.doi.org/10.1353/aad.2012.0630

LaSasso, C., \& Lollis, J. (2003). Survey of Residential and Day Schools for Deaf Students in the United States that Identify Themselves as Bilingual-Bicultural Programs. Journal of Deaf Studies and Deaf Education, 8, 79-91.

Markowitz, J., Carlson, E., Frey, W., Riley, J., Shimshak, A., Heinzen, H., \& Klein, S. (2006). Preschoolers' Characteristics, Services, and Results: Wave 1 Overview Report from the Pre-Elementary Education Longitudinal Study (PEELS). Rockville, MD: Westat.

Mitchell, R. E. (2004). National Profile of Deaf and Hard of Hearing Students in Special Education from Weighted Survey Results. American Annals of the Deaf, 149, 336-349. http://dx.doi.org/10.1353/aad.2005.0004

Mitchell, R. E., \& Karchmer, M. A. (2006). Demographics of Deaf Education: More Students in More Places. American Annals of the Deaf, 151, 95-104. http://dx.doi.org/10.1353/aad.2006.0029

Musyoka, M. M., \& Clark, M. D. (2015). Teachers' Perceptions of Individualized Education Program (IEP) Goals and Related Services. Journal of Developmental and Physical Disabilities. http://dx.doi.org/10.1007/s10882-015-9462-0

Myers, C., Clark, M. D., Musyoka, M. M., Anderson, M. L., Gilbert, G. L., Agyen, S., \& Hauser, P. C. (2010). Black Deaf Individuals' Reading Skills: Influence of ASL, Culture, Family Characteristics, Reading Experience, and Education. American Annals of the Deaf, 155, 449-457.

Nover, S. M. (2000). History of Language Planning in Deaf Education: The 19th Century (Unpublished Doctoral Dissertation). Tucson: University of Arizona.

Qi, S., \& Mitchell, R. E. (2011). Large-Scale Academic Achievement Testing of Deaf and Hard of Hearing Students: Past, Present, and Future. Journal of Deaf Studies and Deaf Education, 17, 1-18.

Spencer, P. E., \& Marschark, M. (2010). Evidence-Based Practice in Educating Deaf and Hard of Hearing Students. New York: Oxford University Press. 